\title{
Ability of bivariate cytokeratin and deoxyribonucleic acid flow cytometry to determine the biologic aggressiveness of resectable non-small cell lung cancer
}

Hiroshi Otsuka, MD

Sadao Funai, MD

Tatsuya Azumi, MD

Satoshi Hara, MD

Kiyotaka Okuno, MD

Masayuki Yasutomi, MD

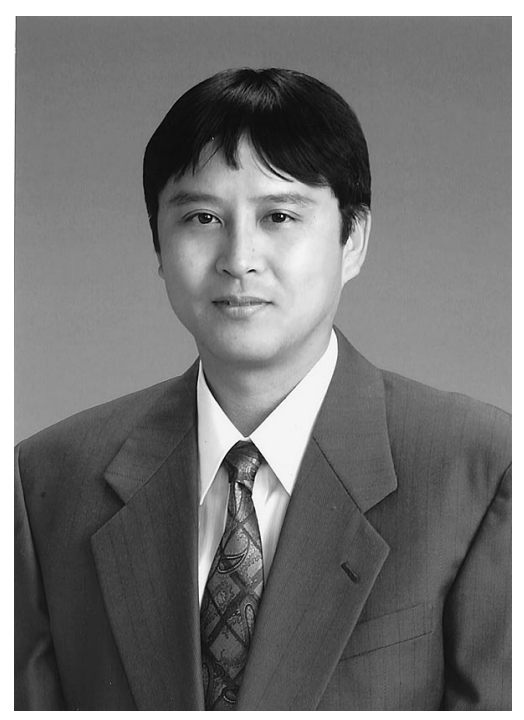

Dr Otsuka

Objective: The purpose of this study was to clarify the significance of bivariate cytokeratin and DNA flow cytometry for analysis of the biologic aggressiveness of resectable non-small cell lung cancer.

Methods: In 92 patients who underwent curative operations, the DNA ploidy status and S-phase fractions of the cancer cell populations inside the tumors were analyzed by a cytokeratin gating technique with paraffin-embedded specimens and were correlated with the surgical results.

Results: Ninety tumors yielded assessable DNA histograms. DNA diploidy was detected in 25 tumors with a mean S-phase fraction of $14.3 \% \pm 4.7 \%$, and DNA aneuploidy was detected in 65 tumors with a mean S-phase fraction of $15.1 \% \pm$ $7.1 \%$. The 5-year overall and recurrence-free survivals were $73.3 \%$ and $70.3 \%$, respectively. Multivariate analysis showed that only TNM staging was a prognostic factor after surgery. There was a negative correlation between the logarithms of $S$-phase fraction and the disease-free interval for 22 patients with proven recurrence $(P=.006)$. The tumors with high S-phase fractions recurred more rapidly than did those with low S-phase fractions.

Conclusion: In a bivariate analysis of cytokeratin and DNA flow cytometry in resectable non-small cell lung cancer, the S-phase fraction appeared to be correlated with the disease-free interval. However, DNA ploidy and S-phase fraction were not predictive of either recurrence or survival after operation. Thus DNA flow cytometry may be of limited use for the analysis of the biologic aggressiveness of lung cancer.

From the First Department of Surgery, Kinki University School of Medicine, Osaka, Japan.

Received for publication May 14, 2001; revisions requested Dec 12, 2001; revisions received Dec 26, 2001; accepted for publication Dec 27, 2001.

Address for reprints: Hiroshi Otsuka, MD, First Department of Surgery, Kinki University School of Medicine, 377-2 Ohnohigashi, Osaka-sayama, Osaka 589-8511, Japan (E-mail: hiroshi@otsuka-japan.com).

J Thorac Cardiovasc Surg 2002;124:293-8

Copyright $(9) 2002$ by The American Association for Thoracic Surgery

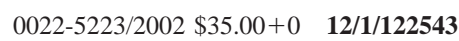

doi:10.1067/mtc.2002.122543

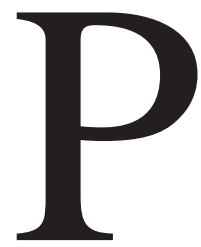

rimary lung cancer has recently become the most common cause of cancer-related death in Japan, and the incidence of this malignancy continues to rise. ${ }^{1}$ Moreover, the marked biologic aggressiveness of lung cancer causes patients to have a poor prognosis despite vigorous treatment. The surgical removal of a lung tumor offers a chance for cure, but the overall survival after resection for patients with nonsmall cell lung cancer (NSCLC) is far from satisfactory. To improve the prognosis of lung cancer, good biomarkers that can be used to guide treatment strategy must be identified, and an innovative multimodal approach that includes effective adjuvant therapy needs to be developed.

DNA ploidy and proliferative activity analyzed by flow cytometry have been established as useful indicators for the biologic aggressiveness of various neoplasms. ${ }^{2,3}$ Because flow cytometry is fast and quantitative, it has the potential to be 

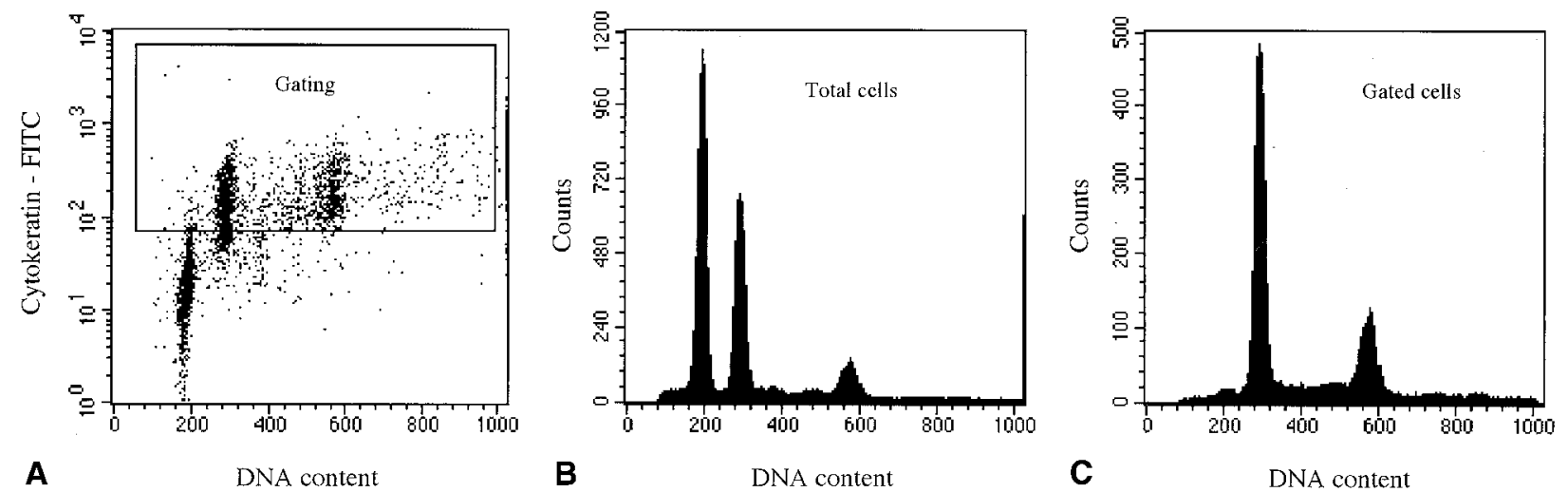

Figure 1. Bivariate cytokeratin and DNA flow cytometry. A, Dot plot of DNA content (x-axis) versus cytokeratin immunofluorescence ( $y$-axis). Box indicates gate for cytokeratin immunoreactivity. B, DNA histogram of total cells with SPF of $12.8 \%$. C, DNA histogram of cytokeratin-positive cells with SPF of $14.1 \%$.

a reliable method for investigators. The reliability of the data measured by flow cytometry may depend strongly on the quality of the sample, rather than on the capability of the cytometer. In practice, the data from cancer tissue include errors caused by stromal cells and infiltrating lymphocytes inside the tumors, and this inaccuracy may have affected the results in previous studies of proliferative activities. ${ }^{4}$ Recently, an immunofluorescent staining step for the cytokeratins of cancer cells has been adopted in the preparation for flow cytometry to detect only cancer cells and not nonepithelial cells, and this has provided more accurate cancerspecific analyses of clinical specimens. 5,6

The aim of this study was to clarify the ability of bivariate cytokeratin and DNA flow cytometry with paraffinembedded specimens to predict the biologic aggressiveness of resectable NSCLC. Accordingly, the associations of tumor DNA ploidy and S-phase fraction (SPF) with the surgical prognoses were assessed. Furthermore, to verify whether tumors with a high proliferative activity grow faster and recur earlier, the disease-free intervals (DFIs) of patients with recurrence after surgery were correlated with their SPF values.

\section{Patients and Methods}

\section{Patients}

This study was performed on 92 patients with primary NSCLC who underwent curative operations and received no induction therapy between January 1, 1993, and December 31, 1996, at the University Hospital, Kinki University School of Medicine, Osaka, Japan. Written, informed consent was obtained from all patients. The patients were reexamined every 3 months for the first 2 years and at an interval of 6 months thereafter, according to the routine follow-up scheme. The follow-up records updated to December 31,2000 , were used for this study.

\section{Flow Cytometry}

From each formalin-fixed and paraffin-embedded specimen obtained from surgically resected lung carcinoma, 4- $\mu \mathrm{m}$ thick slices for hematoxylin and eosin staining and $70-\mu \mathrm{m}$ thick slices for flow cytometry were prepared. After the $70-\mu \mathrm{m}$ sections were removed from paraffin and rehydrated, the tumor-enriched areas were cut off from the sections during viewing of the corresponding hematoxylin and eosin stained area. The samples were incubated with $0.1 \%$ collagenase (Worthington Biochemical Corporation, Lakewood, $\mathrm{NJ}$ ) in phosphate-buffered saline solution, $\mathrm{pH} 7.4$, with $1 \%$ bovine serum albumin at $37^{\circ} \mathrm{C}$ overnight. After washing in phosphate-buffered saline solution, samples were digested with $0.2 \%$ pepsin in $1 \mathrm{~N}$ hydrochloric acid and $0.9 \%$ saline solution for 20 minutes at $37^{\circ} \mathrm{C}$. The digested samples were filtered through a nylon mesh and washed in saline solution buffered with tris(hydroxymethyl)aminomethane, $\mathrm{pH} 7.4$, supplemented with $1 \%$ bovine serum albumin (BSA-TBS). Finally, the single cells were suspended in $100 \mu \mathrm{L}$ of BSA-TBS. The suspensions were incubated with $20 \mu \mathrm{L}$ of the monoclonal anticytokeratin antibody reagent (1:500) clone C-11 (Sigma, St Louis, Mo) or MOPC-21 (Sigma), an isotype control reagent of mouse immunoglobulin G1, for 90 minutes at $4^{\circ} \mathrm{C}$. The samples then were incubated sequentially with $20 \mu \mathrm{L}$ of a fluorescein isothiocyanate-conjugated antimouse immunoglobulin $\mathrm{G}$ antibody reagent and $5 \mu \mathrm{g}$ of 7 -aminoactinomycin D (Sigma) for 30 minutes at room temperature. After washing, $5 \times 10^{6}$ cells were resuspended in $1 \mathrm{~mL}$ of BSA-TBS. The samples were analyzed with a FACS Calibur (Becton Dickinson, San Jose, Calif). Fluorochromes were excited with a single 488-nm argon laser. Fluorescein isothiocyanate fluorescence was detected through a $530 \pm 15 \mathrm{~nm}$ band-pass filter, and 7-aminoactinomycin D fluorescence was detected through a 650-nm longpass filter. For each sample at least 30,000 events were counted. Samples with a coefficient of variation of more than $8 \%$ were excluded from the flow cytometric analyses, according to the recommendation for useful S-phase determinations by Shankey and associates. ${ }^{4}$ The acquired data were analyzed with ModFit software (version 2.0; Verity Software House, Topsham, Maine). 
TABLE 1. Pathologic factors and DNA flow cytometric measurements

\begin{tabular}{|c|c|c|c|c|c|c|}
\hline \multirow[b]{2}{*}{ Factors } & \multicolumn{3}{|c|}{ DNA ploidy pattern } & \multirow[b]{2}{*}{$\begin{array}{c}P \\
\text { value* }^{*}\end{array}$} & \multirow[b]{2}{*}{ SPF $(n=90)$} & \multirow[b]{2}{*}{$\begin{array}{c}\boldsymbol{P} \\
\text { valuet }\end{array}$} \\
\hline & $\begin{array}{l}\text { All patients } \\
(\mathrm{n}=92)\end{array}$ & $\begin{array}{l}\text { Diploid } \\
(\mathrm{n}=25)\end{array}$ & $\begin{array}{c}\text { Aneuploid } \\
\text { (n }=65)\end{array}$ & & & \\
\hline Histologic type & & & & .33 & & .32 \\
\hline Adenocarcinoma & 44 & 10 & 32 & & $13.6 \% \pm 6.6 \%$ & \\
\hline $\begin{array}{l}\text { Squamous cell } \\
\text { carcinoma }\end{array}$ & 35 & 12 & 23 & & $15.5 \% \pm 5.5 \%$ & \\
\hline $\begin{array}{l}\text { Adenosquamous } \\
\text { carcinoma }\end{array}$ & 8 & 3 & 5 & & $16.8 \% \pm 8.6 \%$ & \\
\hline Large cell carcinoma & 5 & 0 & 5 & & $18.2 \% \pm 8.6 \%$ & \\
\hline Primary tumor $(\mathrm{T})$ & & & & .25 & & .71 \\
\hline pT1 & 33 & 8 & 24 & & $14.9 \% \pm 7.6 \%$ & \\
\hline pT2 & 41 & 10 & 30 & & $15.4 \% \pm 5.9 \%$ & \\
\hline pT3 & 15 & 7 & 8 & & $13.9 \% \pm 6.5 \%$ & \\
\hline pT4 & 3 & 0 & 3 & & $12.7 \% \pm 2.4 \%$ & \\
\hline Regional lymph nodes (N) & & & & .64 & & .14 \\
\hline pNO & 68 & 17 & 49 & & $14.4 \%+6.4 \%$ & \\
\hline pN1 & 11 & 3 & 8 & & $13.6 \% \pm 7.0 \%$ & \\
\hline pN2 & 13 & 5 & 8 & & $18.2 \% \pm 6.1 \%$ & \\
\hline Pathologic stage & & & & .27 & & .69 \\
\hline IA & 27 & 6 & 20 & & $13.8 \% \pm 7.2 \%$ & \\
\hline IB & 28 & 6 & 21 & & $15.2 \% \pm 5.8 \%$ & \\
\hline IIA & 2 & 0 & 2 & & $13.8 \% \pm 8.4 \%$ & \\
\hline IIB & 18 & 6 & 12 & & $14.7 \% \pm 6.8 \%$ & \\
\hline IIIA & 14 & 7 & 7 & & $16.9 \% \pm 7.1 \%$ & \\
\hline IIIB & 3 & 0 & 3 & & $12.7 \% \pm 2.4 \%$ & \\
\hline
\end{tabular}

SPF is shown as mean \pm SD.

${ }^{*} P$ value for difference in DNA ploidy.

$\dagger P$ value for difference in SPF distribution.

The SPF was calculated from a DNA histogram of the cells gated for cytokeratin positivity (Figure 1). The SPF values were divided into two groups: a high-SPF group, defined as having SPF greater than the median of all assessable tumors, and a low-SPF group, defined as having SPF less than the median.

\section{Statistical Analysis}

Where appropriate, the data were expressed as mean \pm SD. Differences between two sets of data were tested with the $t$ test, the Mann-Whitney test, or the Kruskal-Wallis test for continuous variables and with the $\chi^{2}$ test for categorical variables. Correlations between two variables were evaluated with the Spearman rank correlation coefficient. The probability of cumulative cancerrelated survival was calculated by the Kaplan-Meier method. Patients who died of unrelated causes were treated as censored cases. Differences in survival were tested with the log-rank test for univariate analysis and with the Cox's proportional hazard model for multivariate analysis.

\section{Results}

The patient population consisted of 70 male and 22 female patients, with a mean age of 63.4 years (range 27-82 years). The lung tumors were histologically classified according to the World Health Organization criteria as follows: adenocarcinoma $(\mathrm{n}=44)$, squamous cell carcinoma $(\mathrm{n}=35)$, adenosquamous carcinoma $(\mathrm{n}=8)$, and large cell carcinoma $(\mathrm{n}=5) .{ }^{7}$ The disease status was determined according to the TNM staging system: stage IA $(n=27)$, stage IB $(\mathrm{n}=28)$, stage IIA $(\mathrm{n}=2)$, stage IIb $(\mathrm{n}=18)$, stage IIIA $(\mathrm{n}=14)$, and stage IIIB $(\mathrm{n}=3)$ (Table 1). ${ }^{8}$ All patients underwent a curative operation combined with mediastinal lymphadenectomy. A lobectomy was performed in 83 patients, bilobectomy was performed in 2 patients, and pneumonectomy was performed in 7 patients. Among the lobectomy procedures, 8 patients underwent extended resections with removal of the involved chest wall and 1 patient had the involved pericardium removed. The median follow-up period was 44.7 months (range 1-83 months). Twenty-two patients had disease recurrence, and 27 patients died. There were 5 operative deaths, 17 cancer-related deaths, and 5 unrelated deaths.

Of all 92 tumors, 2 tumors had DNA histograms with a coefficient of variation greater than $8.0 \%$ and were therefore excluded. The remaining 90 tumors yielded adequate DNA histograms, with a mean coefficient of variation of $6.3 \pm$ 1.2. DNA diploidy was detected in 25 tumors and DNA aneuploidy was detected in 65 tumors. The mean SPF of the 90 analyzable tumors was $14.94 \% \pm 6.5 \%$, and the median 
TABLE 2. Multivariate analysis of independent prognostic factors after surgical therapy according to the Cox proportional hazards model

\begin{tabular}{|c|c|c|c|c|c|c|}
\hline \multirow[b]{2}{*}{ Variable } & \multicolumn{3}{|c|}{ Overall survival } & \multicolumn{3}{|c|}{ Recurrence-free survival } \\
\hline & $\begin{array}{c}\text { Hazard } \\
\text { ratio }\end{array}$ & $\begin{array}{c}95 \% \text { Confidence } \\
\text { interval }\end{array}$ & $P$ value & $\begin{array}{l}\text { Hazard } \\
\text { ratio }\end{array}$ & $\begin{array}{c}95 \% \text { Confidence } \\
\text { interval }\end{array}$ & $P$ value \\
\hline \multicolumn{7}{|l|}{ Histologic type } \\
\hline $\begin{array}{l}\text { Adenocarcinoma } \\
(\mathrm{n}=42)\end{array}$ & 3.2 & $0.7-13.5$ & .11 & 1.2 & $0.4-3.2$ & .77 \\
\hline $\begin{array}{l}\text { Squamous cell } \\
\text { carcinoma }(\mathrm{n}=33)\end{array}$ & 1 & & & 1 & & \\
\hline \multicolumn{7}{|l|}{ Pathologic stage } \\
\hline$I(\mathrm{n}=52)$ & 1 & 1 & & & & \\
\hline II $(\mathrm{n}=20)$ & 1.6 & $0.3-8.5$ & .57 & 1.8 & $0.5-6.0$ & .30 \\
\hline III $(n=15)$ & 21.2 & $5.1-86.7$ & $<.0001$ & 5.8 & $1.9-17.2$ & .001 \\
\hline \multicolumn{7}{|l|}{ DNA ploidy pattern } \\
\hline Diploid $(\mathrm{n}=24)$ & 1 & 1 & & & & \\
\hline Aneuploid $(\mathrm{n}=61)$ & 4.2 & $0.8-20.0$ & .07 & 2.5 & $0.8-7.8$ & .10 \\
\hline \multicolumn{7}{|l|}{$\overline{S P F}$} \\
\hline $\begin{array}{l}\text { Low-SPF group } \\
(\mathrm{n}=44)\end{array}$ & 1 & 1 & & & & \\
\hline $\begin{array}{l}\text { High-SPF group } \\
(\mathrm{n}=41)\end{array}$ & 1.5 & $0.3-6.2$ & .58 & 1.5 & $0.5-4.3$ & .43 \\
\hline
\end{tabular}

was $14.6 \%$. The mean SPFs of the DNA diploid and aneuploid tumors were $14.3 \% \pm 4.7 \%$ and $15.1 \% \pm 7.1 \%$, respectively, which were not significantly different $(P=$ .64). Thus DNA diploid and aneuploid tumors had equal proliferative activities. Moreover, the DNA ploidy and SPF were also independent of the conventional pathologic factors (histologic type, TNM classification, and pathologic stage; Table 1).

Survival after surgery was analyzed for 87 patients (excluding the 5 operative deaths). The 5 -year overall survival and recurrence-free survivals for all 87 patients were $73.3 \%$ and $70.3 \%$, respectively. According to histologic type, the 5 -year overall and recurrence-free survivals were $68.3 \%$ and $71.9 \%$ for the 42 patients with adenocarcinoma, $80.9 \%$ and $70.5 \%$ for the 33 with squamous cell carcinomas, $80.0 \%$ and $62.5 \%$ for the 8 with adenosquamous cell carcinomas, and $75.0 \%$ and $75.0 \%$ for the 4 with large cell carcinomas, respectively. The histologic type did not significantly influence survival. According to the pathologic staging, the 5 -year overall and recurrence-free survivals were $83.7 \%$ and $81.2 \%$ for the 52 patients with stage I disease, $71.4 \%$ and $70.2 \%$ for the 20 with stage II disease, and $39.7 \%$ and $34.3 \%$ for the 15 with stage III disease, respectively. Patients with stage I and III disease had a significant difference in overall survival $(P=.0003)$, as did those with stage II and III disease $(P=.03)$. The patients with stage I and III disease also had a significant difference in recurrence-free survival $(P=.0006)$. According to DNA ploidy, the 24 patients with DNA diploid tumors had 5-year overall and recurrence-free survivals of $88.9 \%$ and $80.8 \%$, respectively.
The 61 patients with DNA aneuploid tumors had 5-year overall and recurrence-free survivals of $69.3 \%$ and $67.5 \%$, respectively. Those with DNA diploid tumors tended to have a better prognosis than did those with DNA aneuploid tumors, but the differences in overall and recurrence-free survivals were not significant $(P=.15$ and $P=.26$, respectively). For the analysis of proliferative activity, the prognoses of the high- and low-SPF groups (above and below the median SPF, respectively) were compared. The high-SPF group $(n=41)$ had 5-year overall and recurrencefree survivals of $77.8 \%$ and $68.7 \%$, respectively. The lowSPF group $(n=44)$ had 5-year overall and recurrence-free survivals of $73.8 \%$ and $74.0 \%$, respectively. The high- and low-SPF groups had statistically equivalent overall and recurrence-free survivals $(P=.82$ and $P=.27$, respectively). Multivariate analysis showed that only TNM staging was a prognostic factor after surgery and that DNA ploidy and proliferative activity were not significant predictors (Table 2).

The DFIs from surgery to documented recurrence in 22 patients were correlated with the DNA flow cytometric parameters. The 4 patients with DNA diploid tumors had a mean DFI of $17.5 \pm 7.0$ months, whereas the 18 with DNA aneuploid tumors had a mean DFI of $17.0 \pm 11.9$ months. There was no significant difference in the DFI between those with DNA diploid and aneuploid tumors $(P=.76)$. The high-SPF group $(\mathrm{n}=12)$ had a mean DFI of $10.8 \pm 3.6$ months, whereas the low SPF group $(n=10)$ had a mean DFI of $24.5 \pm 12.4$ months. The DFIs of the high-SPF group were significantly shorter than those of the low-SPF 


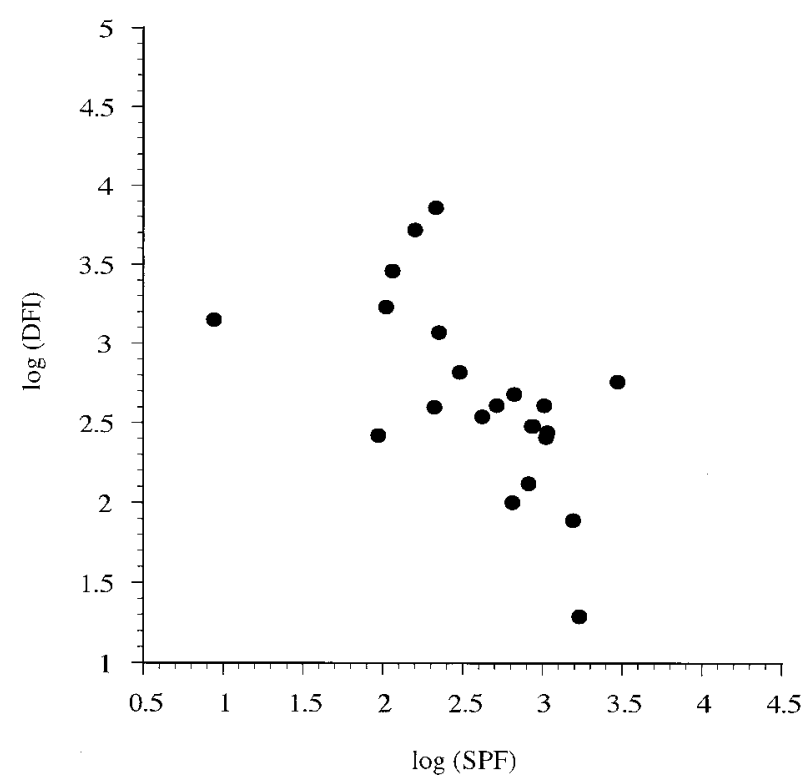

Figure 2. Correlation between natural logarithms of SPF (as percentage) and DFI (in months) among the patients with recurrence after surgery. These variables have significant negative correlation $(P=.006)$.

group $(P=.003)$. There was a significant negative correlation between the logarithms of SPF and DFI ( $p=0.006)$, which indicates that the SPF was inversely proportional to the DFI (Figure 2).

\section{Discussion}

Analyses of the cell kinetics and various markers of cell proliferation may be reliable approaches to study the biologic aggressiveness of cancer.2,3 To date, the development of programs that use the mathematic models to calculate the cell cycle fractions from a DNA histogram and a process for paraffin-embedded specimens reported by Hedley and coworkers ${ }^{9}$ has led to the widespread clinical use of DNA flow cytometric analysis of cell proliferation. However, the downside to this rapid evolution is variability in sample preparation, which may cause discrepancies in reported results. It was therefore hoped that a standard, universally used procedure would be established. , $^{10}$

One of the technical problems in cell cycle analysis from a DNA histogram is the presence of nontumor cells inside tumors. When the population of nontumor cells is a significant percentage of the total, a large error in the flow cytometric data may result. To diminish these errors, the technique of cancer-specific flow cytometry with cytokeratin gating was recently established. Cytokeratins, a family of intermediate filament proteins, are components of epithelial cytoskeletons. This technique enables one to gate cancer cells differently from nonepithelial cells and can be conducted with paraffin-embedded tissue. ${ }^{5,6}$ In the strict sense, however, this method cannot provide a cancer-specific analysis, because normal epithelial cells inside tumors have cytokeratins and can pass through the gate operation.

The establishment of a model to simulate tumor growth is helpful for predicting the clinical prognoses of patients with malignant tumors. Steel reported that the actual volume doubling time $\left(\mathrm{T}_{\text {act }}\right)$ is given by the following function: $\mathrm{T}_{\mathrm{act}}=\lambda \cdot \mathrm{T}_{\mathrm{s}} /[\mathrm{SPF} \cdot(1-\phi)]$, where $T_{\mathrm{s}}$ is the duration of DNA synthesis, $\lambda$ is the correction factor, and $\phi$ is the cell loss factor. ${ }^{11,12}$ Furthermore, taking logarithms of this equation leads to the following equivalent expression: log$\left(\mathrm{T}_{\mathrm{act}}\right)=\log \left[\lambda \cdot \mathrm{T}_{\mathrm{s}} /(1-\phi)\right]-\log (\mathrm{SPF})$. This study, which was performed under the assumption that the DFI is equivalent to $\mathrm{T}_{\mathrm{act}}$ in this theoretical formula, demonstrated that the SPF is inversely correlated with the DFI in NSCLC. Therefore the significance of bivariate cytokeratin and DNA flow cytometry is just rough estimation of the DFI without determination of the SPF and $\mathrm{T}_{\mathrm{s}}$ with a toxic method, such as the tritiated thymidine labeling method or the bromodeoxyuridine labeling method. ${ }^{13-15}$

It has been established that DNA ploidy is generally a good indicator of a tumor's biologic aggressiveness. Some studies of lung cancer that incorporated DNA flow cytometry found that the proliferative activity of DNA aneuploid tumors was higher than that of DNA diploid tumors, ${ }^{16-18}$ whereas other studies found that there were no differences in proliferative activity between DNA ploidy patterns. ${ }^{14,19,20}$ In this study the putative higher proliferative activity of DNA aneuploid tumors could not be proved for NSCLC, even with accurate SPF analysis with the cytokeratin gating method. Previous studies that found DNA diploid tumors to have low proliferative activity may have underestimated the SPF because of the presence of normal cells inside the tumors. To clarify whether there is any difference in the proliferative activity between DNA diploid and aneuploid tumors, a large-scale study will be necessary.

Whether DNA flow cytometry is useful in determining the surgical prognosis of patients with NSCLC remains a matter of debate. ${ }^{2,3,21-27}$ Multivariate analysis in this study revealed that DNA ploidy and proliferative activity were not prognostic factors. The lack of significance of DNA ploidy with respect to both the surgical prognosis and the proliferative activity suggests that there may be little difference, if any, between DNA diploid and aneuploid NSCLC tumors in biologic aggressiveness. Similarly, patients with highSPF tumors had the same prognoses as did those with low-SPF tumors, despite the previously mentioned correlation of SPF with the tumor growth rate. One possible explanation for this is that the SPF is not directly associated with the ability of a tumor to metastasize and therefore would not be a reliable predictor of recurrence. Because our statistical analysis included patients who did not have a recurrence and were possibly cured, there might be no 
significant difference in the survivals between the high- and low-SPF groups. The number of patients with stage II and III disease who had high risk of recurrence was small, and this sample-size issue could have affected other results in this study. Because of the small patient population with stage II disease, censored cases could largely bias the result of prognosis, which was indeed better than universal knowledge. Furthermore, with regard to future treatment strategies, it appears informative that tumors with DNA aneuploidy or high proliferative activity have good responses to chemotherapy. ${ }^{28-30}$ For NSCLC, the prognoses of those with DNA aneuploid or high SPF tumors might be improved by the skillful use of adjuvant therapy.

In conclusion, more accurate DNA flow cytometric analysis of resectable NSCLC with the cytokeratin gating method revealed that the SPF value was correlated inversely with the DFI. However, DNA ploidy and SPF were not useful for predicting either recurrence or survival after surgery. The ability of DNA flow cytometric data to estimate the biologic aggressiveness of NSCLC is limited at best.

\section{References}

1. Health and Welfare Statistics Association. Journal of health and welfare statistics, vol 47, No. 9. Tokyo: Health and Welfare Statistics Association; 2000; p. 48-60.

2. Ross JS. DNA ploidy and cell cycle analysis in cancer diagnosis and prognosis. Oncology. 1996;10:867-87.

3. Merkel DE, McGuire WL. Ploidy, proliferative activity and prognosis. DNA flow cytometry of solid tumors. Cancer. 1990;65:1194-205.

4. Shankey TV, Rabinovitch PS, Bagwell B, Bauer KD, Duque RE, Hedley DW, et al. Guidelines for implementation of clinical DNA cytometry. International Society for Analytical Cytology. Cytometry. 1993; 14:472-7.

5. Leers MP, Theunissen PH, Schutte B, Ramaekers FC. Bivariate cytokeratin/DNA flow cytometric analysis of paraffin-embedded samples from colorectal carcinomas. Cytometry. 1995;21:101-7.

6. Glogovac JK, Porter PL, Banker DE, Rabinovitch PS. Cytokeratin labeling of breast cancer cells extracted from paraffin-embedded tissue for bivanate flow cytometric analysis. Cytometry. 1996;24:260-7.

7. World Health Organization. Histological typing of lung tumours. International Histological Classification of Tumors, No. 1. 2nd ed. Geneva: World Health Organization; 1981.

8. Mountain CF. Revisions in the international system for staging lung cancer. Chest. 1997; 111:1710-7.

9. Hedley DW, Friendlander ML, Taylor IW, Rugg CA, Musgrove EA. Method for analysis of cellular DNA content of paraffin-embedded pathological material using flow cytometry. J Histochem Cytochem. 1983;31:1333-5.

10. Hedley DW. Flow cytometry using paraffin-embedded tissue: five years on. Cytometry. 1989;10:229-41.

11. Steel GG. Cell loss as a factor in the growth rate of human tumours. Eur J Cancer. 1967;3:381-7.
12. Steel GG. Growth kinetics of tumours. Oxford, UK: Clarendon Press; 1977.

13. Blomqvist C, Huuhtanen R, Pan Y, Wiklund T, Tarkkanen M, Virolainen $\mathrm{M}$, et al. Growth rate of lung metastases and S-phase fraction as determined by flow cytometry from the prima tumour in 25 patients with bone or soft-tissue sarcomas. Br J Cancer. 1996;73:1556-9.

14. Teodori L, Trinca ML, Goehde W, Hemmer J, Salvati F, Stomiello G, et al. Cytokinetic investigation of lung tumors using the anti-bromodeoxyuridine (BUdR) monoclonal antibody method: comparison with DNA flow cytometric data. Int J Cancer. 1990;45:995-1001.

15. Kerr KM, Lamb D. Actual growth rate and tumour cell proliferation in human pulmonary neoplasms. Br J Cancer. 1984;50:343-9.

16. Ikonen JT, Ojala A, Salenius JP, Mattila J, Riekkinen H, Wigren T. DNA flow cytometry in surgically treated lung cancer. Scand Cardiovasc J. 1999;33:228-33.

17. Visakorpi T, Holli K, Hakama M. High cell proliferation activity determined by DNA flow cytometry and prognosis in epidermoid lung carcinoma. Acta Oncol. 1995;34:605-9.

18. Tinnemans MM, Schutte B, Lenders MH, Ten Velde GP, Ramaekers FC, Blijham GH. Cytokinetic analysis of lung cancer by in vivo bromodeoxyuridine labeling. Br J Cancer. 1993;67:1217-22.

19. Alvarez-Riesgo JA, Sampedro A, Hernandez R, Folgueras MV, SalasBustamante A, Cueto A. Cell proliferation activity and prognostic index in squamous cell lung carcinoma. Anal Cell Pathol. 1998;16: $233-42$.

20. Costa A, Silvestrini R, Mochen C, Lequaglie C, Boracchi P, Faranda $\mathrm{A}$, et al. P53 expression, DNA ploidy and S-phase cell fraction in operable locally advanced non-small cell lung cancer. Br J Cancer. 1996;73:914-9.

21. Dalquen P, Moch H, Feichter G, Lehmann M, Soler M, Stulz P, et al. DNA aneuploidy, S-phase fraction, nuclear p53 positivity, and survival in non-small-cell lung carcinoma. Virchows Arch 1997;431: 173-9.

22. Kolodziejski L, Niezabitowski A, Gasinska A. Clinical and flow cytometric prognostic factors in surgically treated squamous cell lung cancer. Lung Cancer. 1997;16:173-82.

23. Dyszkiewicz W, Kasprzyk M, Piwkowski C, Gasiorowski L. Prognostic significance of DNA ploidy in squamous cell lung carcinoma: is it really worth it? Ann Thorac Surg. 2000;70:1629-33.

24. Muguerza JM, Diez M, Torres A, Lopez-Asenjo JA, Picardo AL, Gomez A, et al. Prognostic value of flow cytometric DNA analysis in non-small-cell lung cancer: rationale of sequential processing of frozen and paraffin-embedded tissue. World J Surg. 1997;21:323-9.

25. Sahin AA, Ro JY, El-Naggar AK, Lee JS, Ayala AG, Teague K, et al. Flow cytometric analysis of the DNA content of non-small cell lung cancer. Cancer. 1990;65:530-7.

26. Volm M, Hahn EW, Mattern J, Muller T, Vogt-Moykopf I, Weber E. Five-year follow- up study of independent clinical and flow cytometric prognostic factors for the survival of patients with non-small cell lung carcinoma. Cancer Res. 1988;48:2923-8.

27. Tirindelli-Danesi D, Teodori L, Mauro F, Modini C, Botti C, Cicconetti F, et al. Prognostic significance of flow cytometry in lung cancer: a 5-year study. Cancer. 1987;60:844-51.

28. Stal O, Skoog L, Rutqvist LE, Carstensen JM, Wingren S, Sullivan S, et al. S-phase fraction and survival benefit from adjuvant chemotherapy or radiotherapy of breast cancer. Br J Cancer. 1994;70:1258-62.

29. Ojala A, Kallioniemi OP, Wigren T, Kallioniemi A, Mattila J, Lehtinen $\mathrm{M}$, et al. Flow cytometric analysis of tumour DNA profile related to response to radiotherapy and survival in inoperable lung cancer. Acta Oncol. 1990;29:983-8.

30. Abe S, Tsuneta Y, Makimura S, Itabashi K, Nagai T, Kawakami Y. Nuclear DNA content as an indicator of chemosensitivity in small-cell carcinoma of the lung. Anal Quant Cytol Histol. 1987;9:425-8. 